\title{
Sec61 $\beta$ facilitates the maintenance of endoplasmic reticulum homeostasis by associating microtubules
}

\author{
Yimeng Zhu ${ }^{1,2}$, Gangming Zhang ${ }^{1}$, Shaoyu Lin ${ }^{2,3}$, Juanming Shi ${ }^{2}$, Hong Zhang ${ }^{1}$, Junjie Hu ${ }^{1 \bowtie}$ \\ ${ }^{1}$ National Laboratory of Biomacromolecules, CAS Center for Excellence in Biomacromolecules, Institute of Biophysics, \\ Chinese Academy of Sciences, Beijing 100101, China \\ 2 Department of Genetics and Cell Biology, College of Life Sciences, Nankai University, Tianjin 300071, China \\ ${ }^{3}$ Programs in Biomedical and Biological Sciences, University of Southern California, Los Angeles, CA 90089, USA \\ $\triangle$ Correspondence: huj@ibp.ac.cn (J. Hu) \\ Received October 11, 2017 Accepted November 13, 2017
}

\begin{abstract}
Sec61 $\beta$, a subunit of the Sec61 translocon complex, is not essential in yeast and commonly used as a marker of endoplasmic reticulum (ER). In higher eukaryotes, such as Drosophila, deletion of Sec61 $\beta$ causes lethality, but its physiological role is unclear. Here, we show that Sec61 $\beta$ interacts directly with microtubules. Overexpression of Sec61 $\beta$ containing small epitope tags, but not a RFP tag, induces dramatic bundling of the ER and microtubule. A basic region in the cytosolic domain of Sec61 $\beta$ is critical for microtubule association. Depletion of Sec61 $\beta$ induces ER stress in both mammalian cells and Caenorhabditis elegans, and subsequent restoration of ER homeostasis correlates with the microtubule

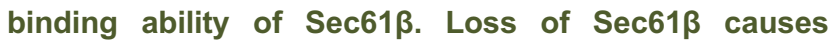
increased mobility of translocon complexes and reduced level of membrane-bound ribosomes. These results suggest that Sec61ß may stabilize protein translocation by linking translocon complex to microtubule and provide insight into the physiological function of ER-microtubule interaction.
\end{abstract}

KEYWORDS ER stress, Microtubule, Sec61 $\beta$, Translocon, Ribosome

Electronic supplementary material The online version of this article (https://doi.org/10.1007/s13238-017-0492-5) contains supplementary material, which is available to authorized users.

\section{INTRODUCTION}

In eukaryotic cells, the endoplasmic reticulum (ER) is composed of membrane tubules and sheets (Shibata et al., 2006). Tubules are $30-50 \mathrm{~nm}$ in diameter and have a high membrane curvature at their cross-section (Hu et al., 2011), which is stabilized by a class of integral membrane proteins including reticulons and DP1/Yop1p (Hu et al., 2008; Voeltz et al., 2006). In contrast, sheets are formed by parallel membranes $\sim 50 \mathrm{~nm}$ apart (Barlowe, 2010). The cisternal spacing is regulated by Climp63 (Shibata et al., 2010), which is proposed to be a luminal bridge, and the surface of the sheets are kept flat, likely by kinectin and p180, which scaffold the membrane as a rod-like structure (Shibata et al., 2010; Zhang and $\mathrm{Hu}, 2016$ ).

The distinct ER shapes are thought to carry out different functions. Tubules are likely involved in membrane trafficking, lipid metabolism, organelle contact, and stress sensing (Wang et al., 2017), whereas sheets are mostly locations for protein synthesis (Shibata et al., 2006; Voeltz et al., 2002). Translating polysomes for ER-targeting proteins prefer the more accommodating surface of ER sheets, and their abundance could dictate the amount of ER sheets (Shibata et al., 2010). Nascent polypeptides, when exiting ribosomes, need to traverse ER membranes through a channel known as the Sec61 complex or translocon (Rapoport, 2007). Therefore, Sec61 and its associating proteins are enriched in ER sheets (Shibata et al., 2010).

Newly synthesized proteins are modified and folded in the $E R$. If misfolded proteins accumulate in the ER, they induce ER stress and activate signaling events known as the unfolded protein response (UPR) (Bernales et al., 2006; Ron 
and Walter, 2007; Schroder and Kaufman, 2005; Walter and Ron, 2011). The UPR consists of three signaling arms: IRE1, PERK, and ATF6. Initially, protective efforts are made, such as increasing chaperones and decreasing translations. Activated IRE1 splices XBP1 mRNA, which is translated into an active transcription factor that up-regulates the levels of chaperones (Calfon et al., 2002; Lee et al., 2002; Yoshida et al., 2001). PERK phosphorylates elF2 $\alpha$ and inhibits translation so that the burden on the ER can be relieved (Harding et al., 2000; Harding et al., 1999), and ATF6 is cleaved into a soluble transcription factor that also helps deal with ER stress (Haze et al., 1999; Yoshida et al., 2001). If the imbalance of proteostasis in the ER is sustained, programmed cell death is triggered (Tabas and Ron, 2011). Indicators for UPR are often used as markers of ER health.

Like many other organelles, the ER, in the form of either tubules or sheets, is closely associated with microtubules (Friedman and Voeltz, 2011; Staehelin, 1997; Terasaki et al., 1986; Voeltz et al., 2002). The microtubule cytoskeleton not only helps position and support ER membranes, but also actively participates in remodeling the ER (Wang et al., 2013). ER tubules are constantly pulled out of existing ER membranes, by either associating with the growing plus end of the microtubule or sliding along the microtubule with molecular motors (Friedman and Voeltz, 2011). When microtubules are depolymerized by nocodazole treatment, the peripheral tubular ER network retracts towards the center of the cell, yielding an ER made up of mostly sheets (Terasaki et al., 1986). Thus, the microtubule network plays an important role in ER morphogenesis.

Several ER-resident proteins that associate with microtubules have been identified. STIM1 binds to the microtubule plus end, moving it closer to its interaction partner on the plasma membrane, Orai (Carrasco and Meyer, 2011; Grigoriev et al., 2008; Park et al., 2009). Tubule-localized REEP1, a homolog of DP1 (also known as REEP5), has a C-terminal microtubule-binding domain, the loss of which causes hereditary spastic paraplegia (Park et al., 2010). ER sheet marker Climp63 also engages microtubules using its cytosolic N-terminus in a phosphorylation-dependent manner (Klopfenstein et al., 1998; Vedrenne et al., 2005). Disruption of the interaction likely alters the mobility of sheetlocalized translocon complex (Nikonov et al., 2007). These findings suggest that the ER-microtubule association has physiological importance. However, the specific roles of such association are not clear.

As described here, we accidently discovered that Sec61 $\beta$, the $\beta$ subunit of the Sec61 translocon complex, interacts directly with microtubules. In the translocon, the $\alpha$ subunit is the pore-forming component, the $y$ subunit hinges the $\alpha$ subunit, and the transmembrane (TM) domain of the $\beta$ subunit attaches in the periphery of the channel. The bacterial homolog of Sec61 $\beta$ is non-essential (Rapoport, 2007). In yeast, double deletion of the two Sec61 $\beta$ homologs (Sb$\mathrm{h} 1 \mathrm{p}$ and Sbh2p) only causes a temperature-sensitive growth defect and can be rescued by the TM domain of the protein
(Feng et al., 2007; Finke et al., 1996). Therefore, Sec61 $\beta$ is better known as a frequently used ER marker (Shibata et al., 2006; Voeltz et al., 2006; Voeltz et al., 2002; Zurek et al., 2011) and a model substrate for tail-anchored insertion into the ER (Abell et al., 2004; Favaloro et al., 2008; Stefanovic and Hegde, 2007). Interestingly, Sec61 $\beta$ is essential for Drosophila development (Valcarcel et al., 1999) and critical for $C$. elegans development. Depletion of Sec61 $\beta$ in mammalian cells and $C$. elegans induces mild ER stress. The microtubule-binding ability of Sec61 $\beta$ is associated with the maintenance of ER homeostasis.

\section{RESULTS}

\section{Overexpressed Sec61 $\beta$ bundles ER and microtubule}

In the process of making various ER markers, we noticed that Sec61 $\beta$ containing a C-terminal HA tag localizes properly in the ER, but its expression dramatically alters the ER morphology (Fig. 1A and 1G); most of the ER becomes swirllike thick tubules. Similar ER patterns have been seen in cells overexpressing ER-bound proteins that can interact with microtubules (Klopfenstein et al., 1998; Miyazaki et al., 2012; Park et al., 2010). When tubulin was visualized in COS-7 cells expressing Sec61 $\beta-\mathrm{HA}$, the microtubule network was drastically rearranged and completely overlapped with the ER network, suggesting an augmented association. The same phenomenon was seen when the HA tag was placed on the N-terminus of Sec61 $\beta$ (Figs. S1A and $1 G$ ). Conversely, in cells expressing $\mathrm{N}$-terminal RFP-tagged Sec61 $1 \beta$, a frequently used version of the ER marker, no ERmicrotubule bundling was observed (Fig. 1B and 1G), similar to untreated cells (Fig. 1C). To rule out artifacts that might be introduced by protein tagging or cell fixation, we co-transfected non-tagged Sec61 $\beta$, ER-DsRed and mEmerald-Ensconsin (microtubule binding protein) into COS-7 cells. Live cell imaging showed same ER-microtubule bundling in transfected cells (Fig. 1D). These results suggest that Sec61 $\beta$ may interact with microtubules and the binding can be prevented with a large tag at the $\mathrm{N}$-terminus.

As a tail-anchored protein, human Sec61 $\beta$ contains an $\mathrm{N}$-terminal cytosolic domain (cytSec61 $\beta$ ) of 70 amino acids (Fig. S1B). To pinpoint the microtubule-associating region in Sec61 $\beta$, we performed a serial truncation of the domain (Fig. 1E). When the first 19 residues were deleted, the Sec61 $\beta$ mutant was still able to bundle microtubules with the ER (Fig. 1F). However, when the deletion was extended to 44 residues, such defects were no longer seen in the ER and microtubule morphology (Fig. 1F). We then removed residues $20-44$ of cytSec61 $\beta$ and found that the mutant failed to tangle the ER and microtubules (Fig. $1 \mathrm{~F}$ and $1 \mathrm{G}$ ). The region of residues 20-44 is enriched with positively charged amino acids. When all six of them (K20, R25, R32, R34, K35, and R42) were substituted by alanine, the mutant Sec61 $\beta-\mathrm{HA}$ no longer linked microtubule to the ER (Fig. $1 \mathrm{~F}$ and $1 \mathrm{G}$ ). In contrast and as expected, when we replaced cytSec61 $\beta$ with a known 
A
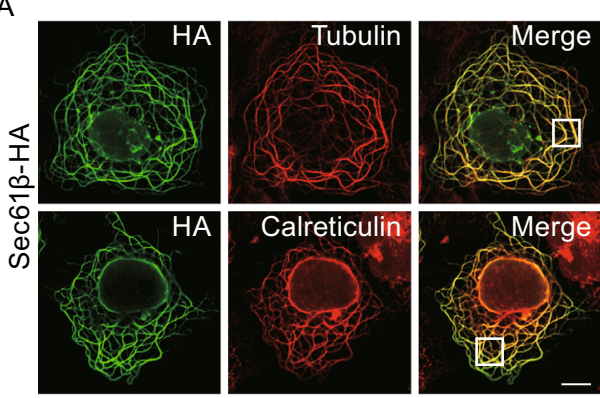

B
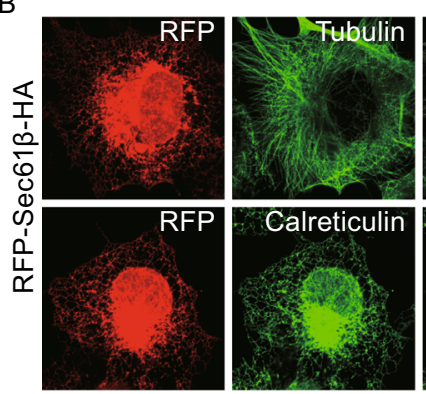

C

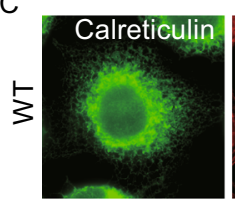

D
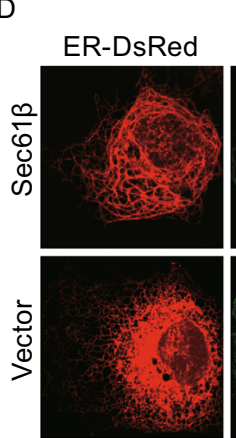

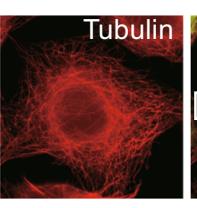

mEmeraldEnsconsin

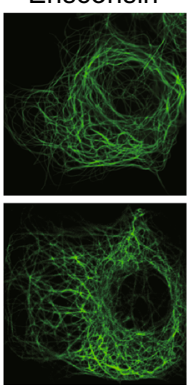

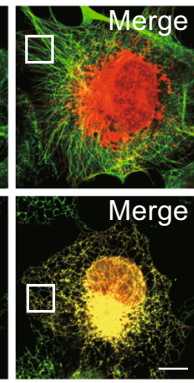
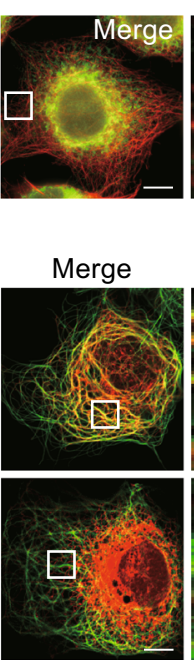
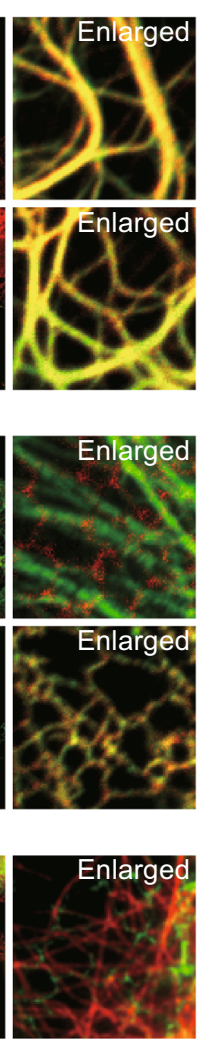

Enlarged

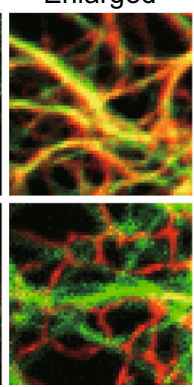

E

Cytoplasmic domain $\square$ TM $\square$ HA tag $\square$ MTB $^{\text {Climp63 }} \square$ RFP

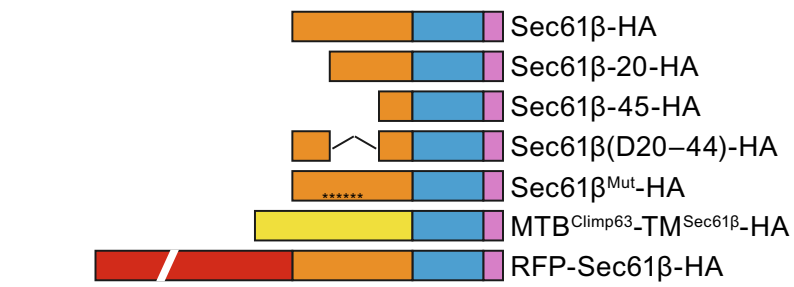

$\mathrm{F}$

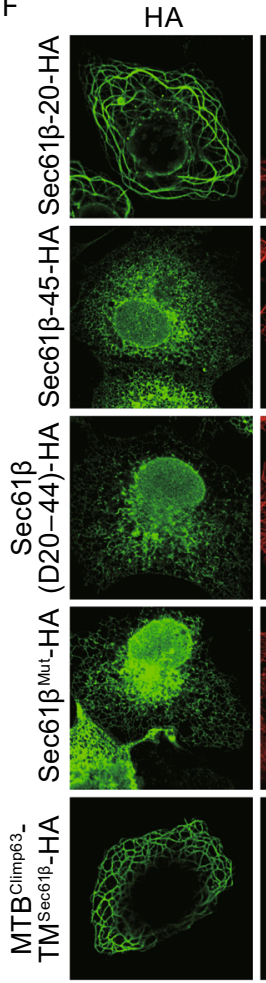

\section{Tubulin}

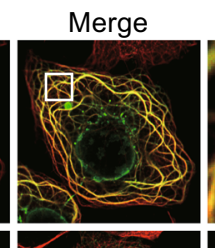

Enlarged
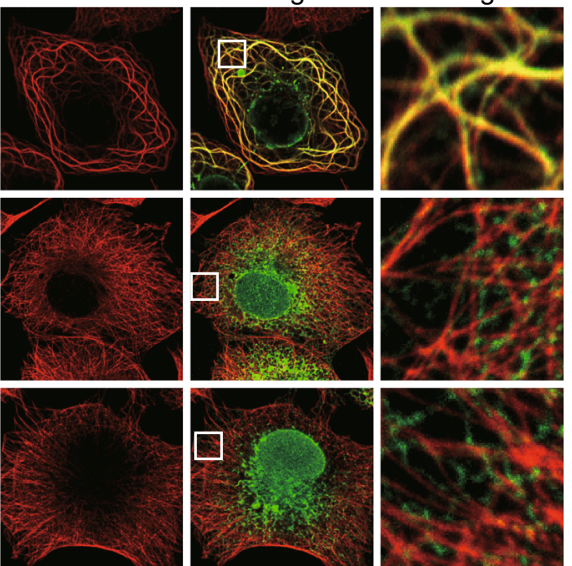

G

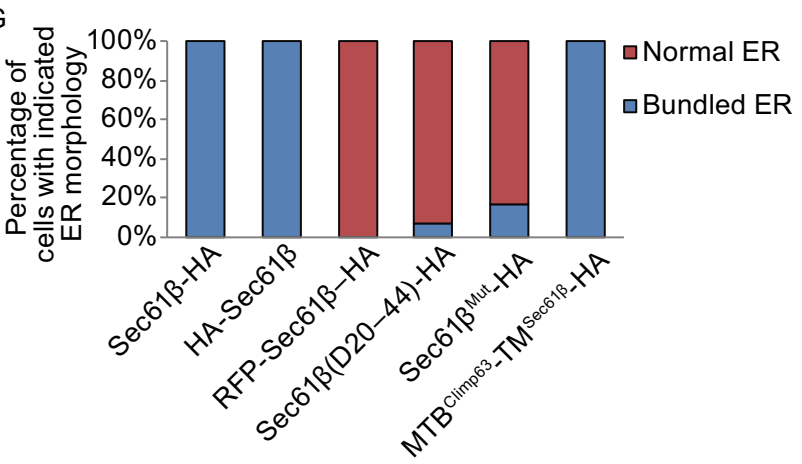

Figure 1. Overexpressed Sec61 $\beta$ induces bundling of the ER and microtubule. (A) COS-7 cells transfected with Sec61 $\beta-H A$ were immunostained for HA (green) and endogenous tubulin or luminal ER protein, calreticulin (red), and visualized by fluorescent confocal microscopy. Insets show the enlargement of the indicated area. (B) As in (A), but with RFP-Sec61 $\beta-H A$ and were immunostained only for tubulin or calreticulin (green). (C) As in (A), but wild type COS-7 cells were immunostained for calreticulin (green) and tubulin (red). (D) COS-7 cells co-transfected with Sec61ß, ER-DsRed (red), and mEmerald-Ensconsin (green) were visualized live by fluorescent confocal microscopy. (E) Domain structures of constructs. $(F)$ As in $(A)$, but with various constructs shown in (E), and were immunostained for HA-epitope (green) and tubulin (red). (G) The ER morphology of samples shown in (A) and (B) was categorized as "bundled" and "normal" respectively. A total of 150 cells were counted for each sample. All graphs were representative of three repetitions. In (A-D) and $(F)$, scale bars are $10 \mu \mathrm{m}$. 
A
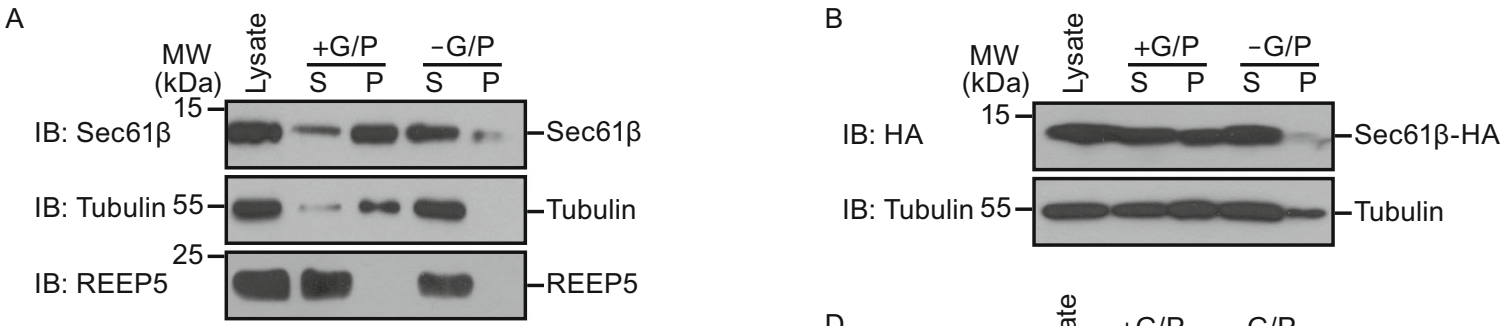

C

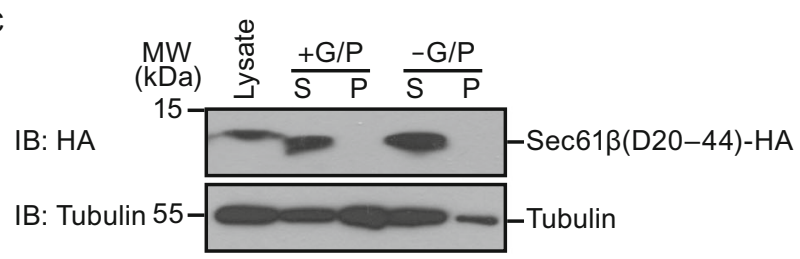

E

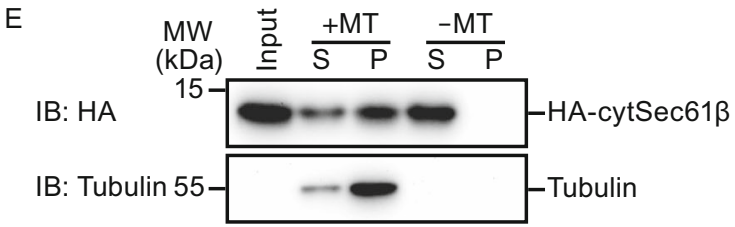

G

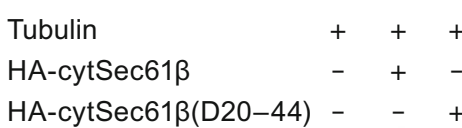

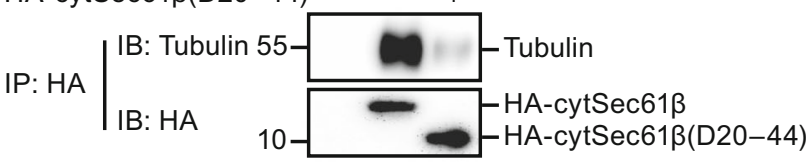

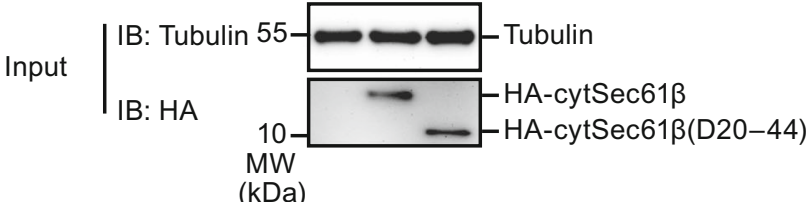

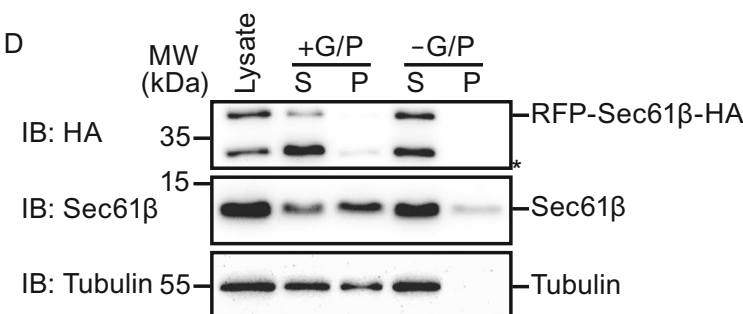

$\mathrm{F}$

IB: HA

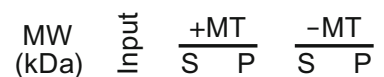

IB: Tubulin 55-

Figure 2. Sec61 $\beta$ interacts with microtubule. (A) COS-7 cells were harvested for microtubule co-sedimentation in the absence or presence of GTP/paclitaxel (G/P). Samples of the supernatant $(S)$ and pellet (P) were analyzed by Western blotting. (B-D) As in (A), but transfected with full length Sec61 $\beta(B)$, Sec61 $\beta$ lacking residues 20-44 (C) or RFP-tagged Sec61 $(D)$. The bands with asterisk ${ }^{*}$ ) may be degraded RFP-Sec61 $\beta$-HA. (E) Purified wild-type HA-cytSec61 $\beta$ was incubated with microtubules (MT) or not, for microtubule co-sedimentation. Samples were analyzed by Western blotting. $(F)$ As in (E), but with HA-cytSec61 $\beta$ lacking residues 20-44. (G) Purified wild-type HA cytSec61 $\beta$ or HA-cytSec61 $\beta$ lacking residues 20-44 was incubated with tubulins and precipitated with anti-HA antibody. The levels of indicated proteins were analyzed with Western blotting.

microtubule-binding (MTB) fragment (residues 1-80 of Climp63), the chimera MTB ${ }^{\text {Climp63 }}-\mathrm{TM}^{\text {Sec613 }}$ behaved the same as Sec61 $\beta-H A$ in gluing the ER and microtubules into swirls (Fig. 1F and 1G). Like all of the truncation mutants, the chimera localized specifically to the ER (Fig. S1C). Notably, alterations of the cytSec61 $\beta$ caused decreased expression level (Fig. S1D). These results suggest that the microtubule-binding site of Sec61 $\beta$ is within a middle region of its cytosolic domain.

\section{Sec61 $\beta$ interacts directly with tubulin}

To confirm the interactions between Sec61 $\beta$ and microtubules, we performed microtubule sedimentation assays.
Endogenous Sec61 $\beta$ co-precipitated with tubulins when the microtubules were reassembled in COS-7 cell lysates in the presence of GTP and paclitaxel, and precipitated in a glycerol cushion (Fig. 2A). Over-expressed wild-type Sec61ß-HA (Fig. 2B), but not the $\Delta 20-44$ mutant (Fig. 2C), also co-sedimented with polymerized microtubule. Consistently, RFPSec61 $\beta$ failed to settle with microtubules, even when endogenous Sec61 $\beta$ did in the same lysates (Fig. 2D). These results confirm that Sec61 $\beta$ interacts with microtubules.

To test whether the association is direct, we used purified proteins to perform microtubule sedimentation assays. Wildtype HA-cytSec61 $\beta$ was efficiently precipitated by microtubules assembled with purified tubulins (Fig. 2E). The 

A $\quad \begin{gathered}\text { MW } \\ (\mathrm{kDa}) \text { shCtrl sh1 sh2 }\end{gathered}$

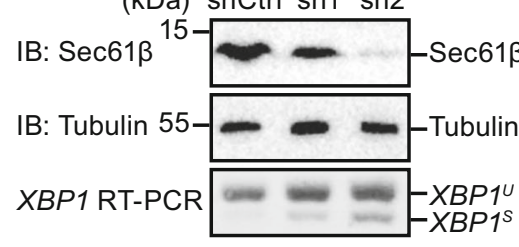

B shCtrl sh2 TG

XBP1 RT-PCR $=-X B P 14$
C

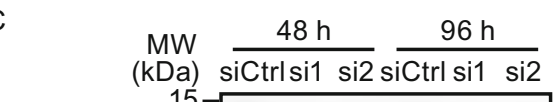

IB: Bip

(kDa) shCtrlsh2

IB: $p$-elF $2 \alpha^{40-\infty-p-e l F 2 \alpha}$

IB: elF2 $\alpha$

-elF2a

IB: Tubulin 55-Tubulin

Figure 3. Depletion of Sec61 $\beta$ triggers ER stress. (A) COS-7 cells were infected with shRNA-expressing viruses. The levels of Sec61 $\beta$ were determined by Western blotting, and the unspliced (U) XBP1 and spliced (S) XBP1 by RT-PCR of XBP1 mRNA were resolved by agarose gel. ER stress markers, including Bip and phosphorylated elF2 $\alpha$, were analyzed by Western blotting. Asterisk ( ${ }^{*}$ ) indicates a nonspecific band. (B) The unspliced (U) XBP1 and spliced (S) XBP1 by RT-PCR of XBP1 mRNA from infected cells or thapsigargin (TG) treated cells were resolved by agarose gel. (C) U2OS cells were transfected with siRNAs of Sec61 13 for $48 \mathrm{~h}$ or 96 $\mathrm{h}$. The levels of Sec61 $\beta$ were determined by Western blotting, and the unspliced XBP1 and spliced XBP1 by RT-PCR of XBP1 mRNA were resolved by agarose gel.

A

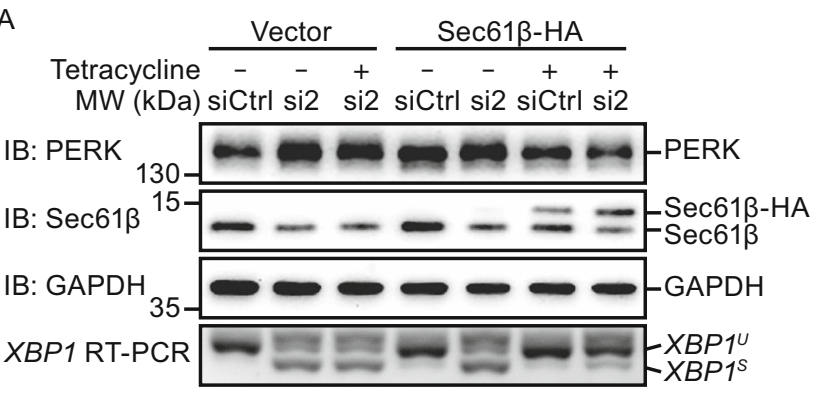

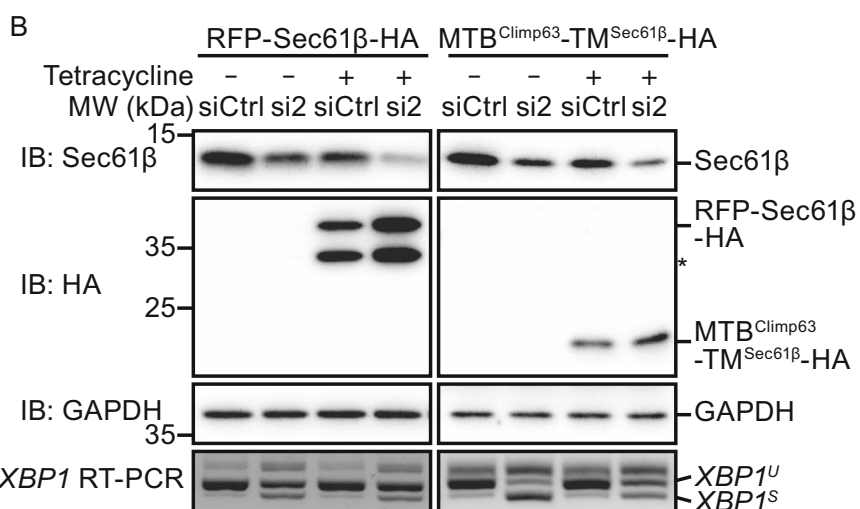

Figure 4. Sec61ß-regulated ER homeostasis requires microtubule binding. (A) SiRNA transfected Flp-In-293 cells were treated with tetracycline as indicated. The samples were analyzed by Western blotting and agarose gel. (B) As in (A), but in cells expressing

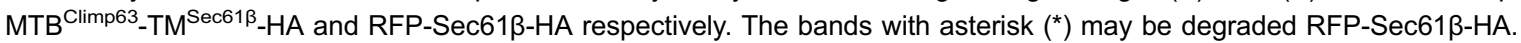

deletion of residues 20-44 again disrupted the interactions (Fig. 2F). Furthermore, when wild-type HA-cytSec61 $\beta$ but not the $\Delta 20-44$ mutant, was incubated with tubulins, anti-HA antibodies precipitated tubulins (Fig. 2G). These results suggest that Sec61 $\beta$ engages tubulin directly in an assembly-independent manner.

\section{Depletion of Sec61 $\beta$ causes ER stress}

To assess the role of Sec61 $\beta$-mediated microtubule association, we depleted Sec61 $\beta$ using RNA interference. Two different shRNAs against Sec61 $\beta$ were individually introduced into COS-7 cells using a viral vector. Sec61 $\beta$ depletion was detected in both samples, with shRNA \#2 being more efficient than \#1 (Fig. 3A). However, no obvious morphological ER defects were seen in these cells (Fig. S2A).
The same applied to microtubules, Golgi, and mitochondria (Fig. S2A). These results coincide with the redundancy of ER-microtubule interactions.

Next, because Sec61ß, as a component of the ER translocon, is associated with the protein synthesis pathway, we tested whether its depletion affects protein homeostasis in the ER. Defective protein production in the ER activates UPR signaling. In Sec61ß-depleted COS-7 cells, splicing of XBP1 mRNA (indicative of IRE1 activation) was detected (Fig. 3A). The level of splicing was more prominent when Sec61 $\beta$ was more efficiently depleted, but overall was moderate compared to that triggered by thapsigargin (TG) treatment (Fig. 3B). Similarly, elF2 $\alpha$ phosphorylation (indicative of PERK activation) was elevated when Sec61 $\beta$ was knocked down (Fig. 3A). XBP1 splicing was also observed when Sec61 $\beta$ was depleted with siRNAs instead of 

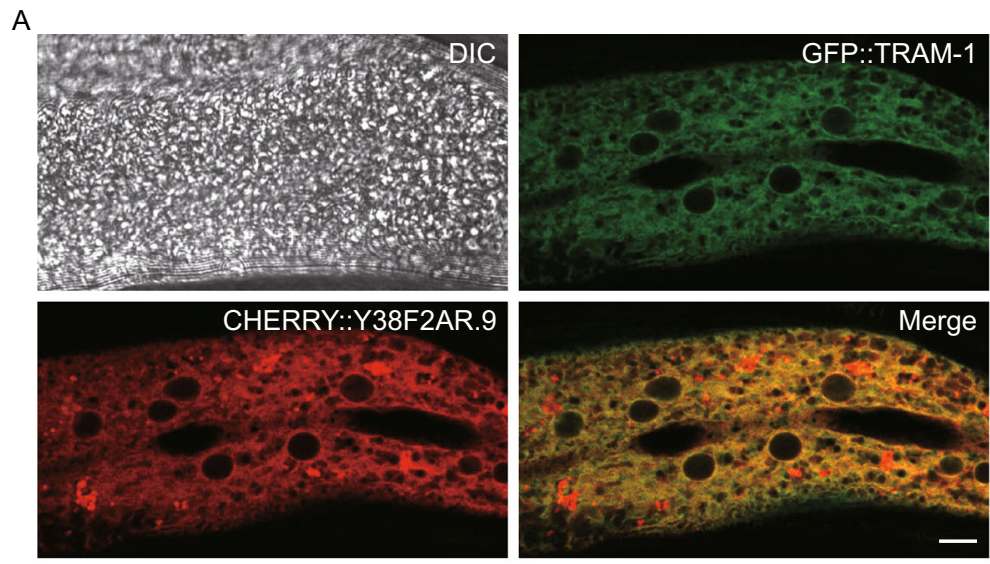

B
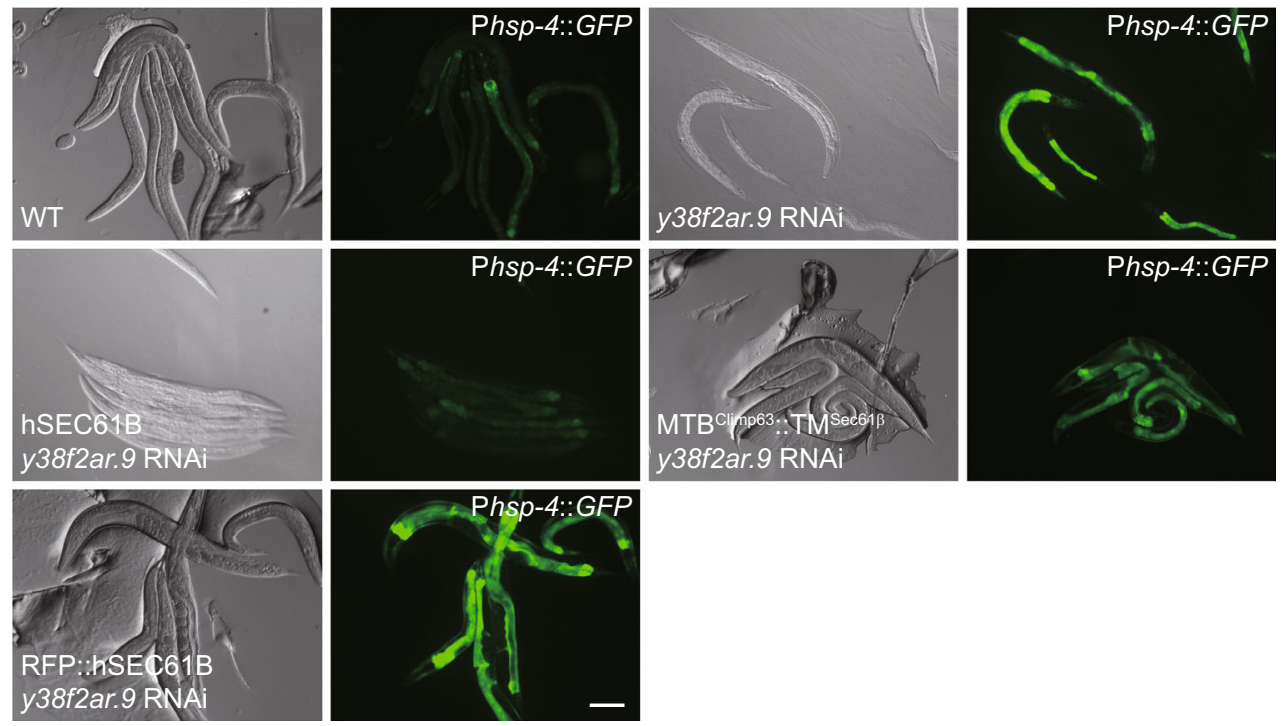

Figure 5. The function of Sec61 $\beta$ is essential and conserved in C. elegans. (A) Fluorescent micrographs of hypodermal cells in gfp::tram-1 worms expressing CHERRY::Y38F2AR.9. DIC, differential interference contrast. Scale bar: $5 \mu$ m. (B) The y38f2ar.9 RNAi was injected into worms carrying Phsp-4::GFP, and GFP fluorescence was assessed. For rescue assay, y38f2ar.9 RNAi was injected into Phsp-4::GFP ER stress reporter worms carrying human SEC61B, MTB ${ }^{\text {Climp63 }}$ TM $^{\text {Sec613 }}$ or RFP-hSEC61B, and GFP fluorescence was assessed. Scale bar: $100 \mu \mathrm{m}$.

shRNAs (Fig. 3C). In contrast, depletion of ER tubule marker REEP1 or sheet marker Climp63 did not cause detectable ER stress (Fig. S2C-E), even though both of them interact with microtubules. These data demonstrate that the loss of Sec61 $\beta$ induces ER stress.

We also tested whether Sec61 $\beta$ regulates ER homeostasis in the context of a multicellular organism. Y38F2AR.9 is the $C$. elegans homolog of Sec61ß. A CHERRY:: Y38F2AR.9 reporter showed that, at the larval stage, Y38F2AR.9 formed a reticular network and accumulated around the nucleus, resembling the pattern of the ER (Fig. 5A). In addition, CHERRY::Y38F2AR.9 co-localized with ER marker GFP::TRAM-1, confirming that Y38F2AR.9 has the same localization as Sec61ß (Fig. 5A). As in Drosophila (Valcarcel et al., 1999), deletion of Y38F2AR.9 caused lethality. Thus, we used RNAi to deplete Y38F2AR.9. Consistently, loss of Y38F2AR.9 caused a significant increase in Phsp-4::GFP expression (Fig. 5B), indicative of the induction of ER stress. These results confirm that the function of Sec61 $\beta$ is essential and conserved in C. elegans.

\section{Microtubule association by Sec61 $\beta$ regulates ER homeostasis}

To probe the role of Sec61ß in the maintenance of ER homeostasis, we tested whether Sec61 $\beta$-mediated microtubule association is critical. To this end, we generated FlpIn-293 cells to stably express wild-type or mutant Sec61 $\beta$ (Fig. S2F). Taken expression levels into consideration (Fig. S1D), we chose two representative mutants: 
A

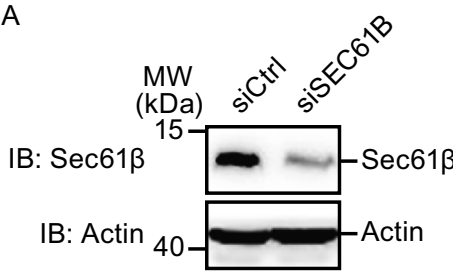

B
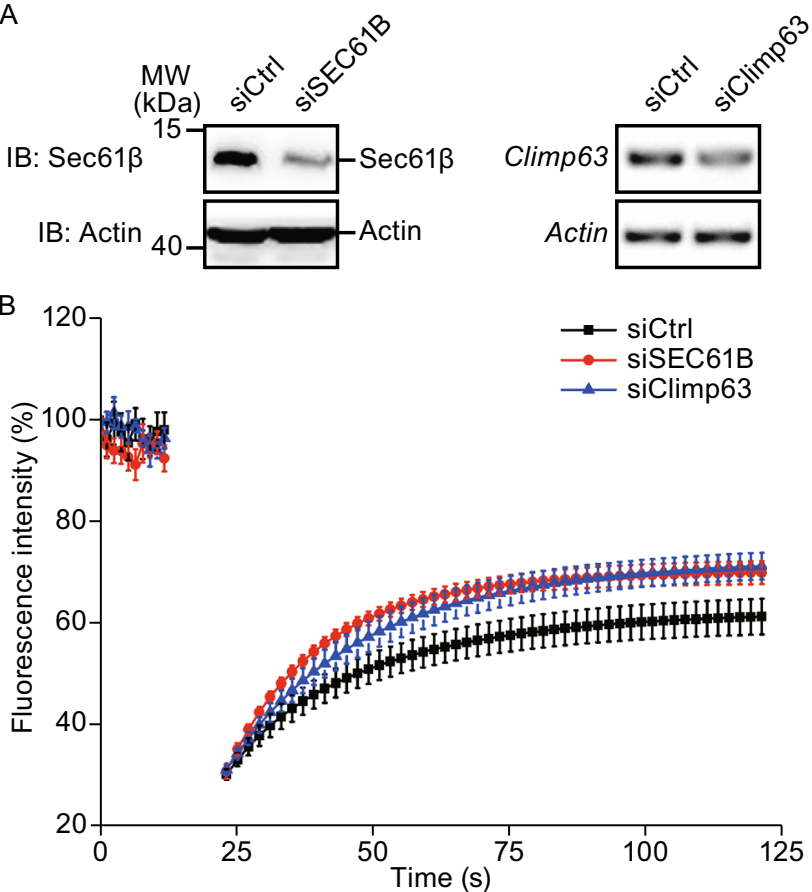

C
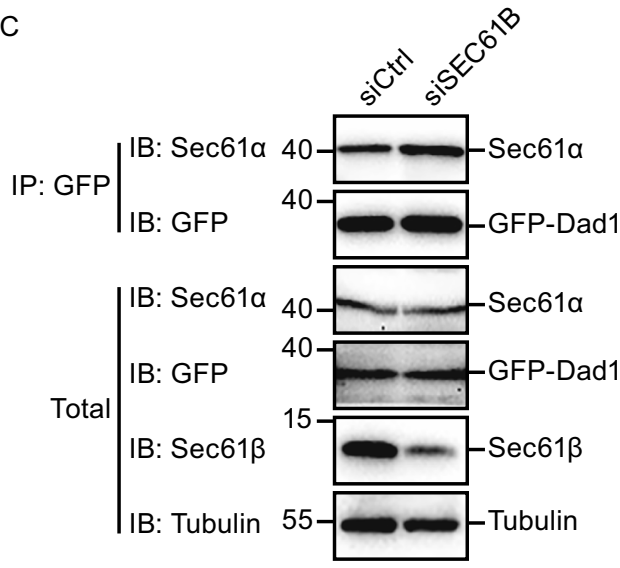

Figure 6. Depletion of Sec61 $\beta$ improves the lateral mobility of translocon complexex. (A) M3/18 cells transfected with siRNA of Sec61 $\beta$ or Climp63 for $48 \mathrm{~h}$ were lyzed for analysis after FRAP. The levels of Sec61 $\beta$ were determined by Western blotting, with actin as a loading control. Climp63 and Actin by RT-PCR were resolved by agarose gel. (B) M3/18 cells in (A) were analyzed by fluorescence recovery after photobleaching assay. The initial fluorescence intensity was set at $100 \%$. Data are mean \pm SEM. ( $n=7$ for control group, 6 for siSEC61B group and 5 for siClimp63 group). (C) M3/18 cells were transfected with siRNA of Sec61 3 for $48 \mathrm{~h}$. The lysates were precipitated with anti-GFP antibody. The levels of indicated proteins were analyzed with Western blotting.

MTB $^{\text {Climp63 }}-\mathrm{TM}^{\text {Sec61ß }}$ (microtubule-binding positive) and RFP-Sec61 $\beta$ (microtubule-binding negative). The ectopic expression of Sec61 $\beta$ was siRNA-resistant and induced by the addition of tetracycline. Meanwhile, endogenous Sec61 $\beta$ was depleted by the transfection of siRNA. As expected, the moderate ER stress caused by Sec61 $\beta$ depletion and judged by $X B P 1$ splicing and PERK phosphorylation was alleviated when Sec61 $\beta-\mathrm{HA}$ was expressed at an equivalent level (Fig. 4A). Notably, transfection of control siRNA or tetracycline treatment per se did not trigger ER stress (Fig. 4A). RFP-Sec61 $\beta$, which does not bind to microtubules, failed to rescue Sec61 $\beta$-related ER stress (Fig. 4B). However, the chimera $M T B^{\text {Climp63 }}-\mathrm{TM}^{\text {Sec61 } \beta}$ was able to partially replace Sec61 $\beta$, maintaining ER proteostasis (Fig. 4B). When we depolymerized microtubules using nocodazole (Fig. S3A), presumably abolishing ER-microtubule interactions, weak ER stress was detected (Fig. S3B and S3C).

To confirm the microtubule-binding role of Sec61 $\beta$ in a physiological setting, we monitored the levels of ER stress in C. elegans upon the expression of various Sec61 $\beta$ constructs. Elevation of the Phsp-4::GFP reporter caused by depletion of Y38F2AR.9 was efficiently inhibited by the expression of human Sec61 $\beta$ under a ubiquitous nfya-1 promoter, which resists RNAi treatments (Fig. 5B). ER stress was partly suppressed when the chimera MTB ${ }^{\text {Climp63. }}$ $\mathrm{TM}^{\text {Sec61 } \beta}$ was introduced, but not when RFP-Sec61 $\beta$ was used (Fig. 5B). Interestingly, vectors containing human SEC61B could only be injected at very low amounts in the rescue experiments, suggesting that the Sec61 $\beta$ level needs to be tightly regulated. Taken together, these results confirm that the maintenance of ER homeostasis is likely linked to interactions between Sec61 $\beta$ and microtubules.

ER-microtubule interaction plays a role in regulating translocon mobility (Nikonov et al., 2007). To test whether Sec61 $\beta$ has similar effect, we utilized M3/18 cells, in which GFP-Dad1 (a subunit of the oligosaccharyltransferase) reflects the lateral mobility of the translocon by being part of the complex (Nikonov et al., 2002). The system was first validated by FRAP analysis of GFP-Dad1 upon depletion of Climp63 (Fig. 6A); as previously reported, the mobility of translocon was increased (Fig. 6B). Consistently, depletion of Sec61 $\beta$ promoted moving of the translocon (Fig. 6A and 6B) without compromising Sec61a-Dad1 association 

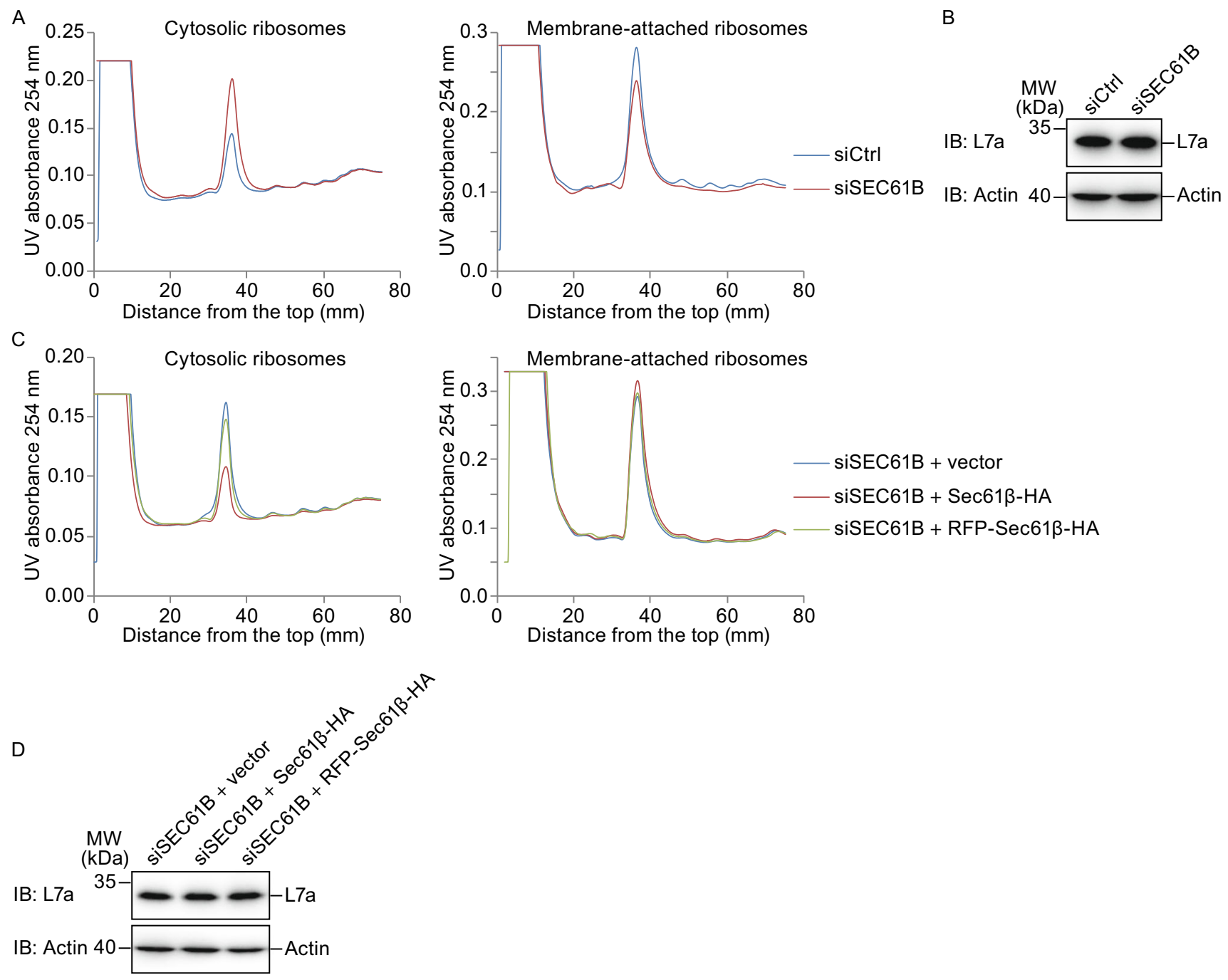

Figure 7. Sec61 $\beta$ stabilizes membrane attachment of ribosomes. (A) Polysome profiles of U2OS cells transfected control siRNA (siCtrl) or siSEC61B\#2. (B) Total lysates from (A) were analyzed by Western blotting, with actin as a loading control. (C) As in (A), but U2OS cells co-transfected siSEC61B\#2 and indicated plasmids. (D) As in (B), but from cells in (C). For all of them, the trends are similar among at least two independent repeats.

(Fig. 6C). These results suggest that microtubule binding by Sec61 $\beta$ likely limits translocon mobility.

Because co-translational translocation requires a stable association between the translating ribosome and translocon, we further tested whether microtubule binding by Sec61 $\beta$ regulates ribosome-translocon complex formation. Cytosolic ribosomes were collected after plasma membrane permeablilization, with the remaining ribosomes considered membrane-bound (i.e., ER-associated through interactions with translocons). When ribosomal profiling was analyzed using density gradients, Sec61 $\beta$-depleted cells contained increased cytosolic ribosomes and decreased membranebound ribosomes compared to cells treated with control siRNA (Figs. 7A and S4A), even though the total amount of ribosomes judged by immunoblotting of ribosomal protein L7a remained unchanged (Fig. 7B). Consistently, RFP-tagged Sec61 $\beta$ failed to restore membrane attachment of ribosomes (Fig. 7C, 7D, and S4B), but the chimera MTB Climp63. $\mathrm{TM}^{\text {Sec613 }}$ succeeded (Fig. S4C-E). These results suggest that Sec61 $\beta$ may facilitate the attachment of ribosomes to translocons using its microtubule-binding ability.

\section{DISCUSSION}

Our results characterize a previously unidentified activity of the cytosolic domain of Sec61 $\beta$. We show that Sec61 $\beta$ interacts directly with microtubules, and is involved in the maintenance of ER homeostasis. Specifically, depletion of 
Sec61 $\beta$ causes ER stress in both $C$. elegans and mammalian cells, and rescue of the stress appear to associate with the microtubule-binding activity, even when the cytosolic domain of Sec61 $\beta$ is replaced by the MTB domain of Climp63. Our results also suggest that the microtubulebinding activity of Sec61 $\beta$ likely stabilizes ribosometranslocon interactions. These findings provide important insights into the physiological role of the ER-microtubule association mediated by Sec61 $\beta$.

Previous work on Sec61 $\beta$ focused mainly on its TM region. As part of the translocon, the TM of Sec61 $\beta$ facilitates the organization of the translocon-associated complex, including the interactions with signal peptidase and Sec62/ 63 (Kalies et al., 1998; Meyer et al., 2000). In yeast, the growth defects caused by double deletion of $\mathrm{SBH} 1$ and $S B H 2$, paralogs of Sec61 $\beta$, can be restored by expression of only the TM region of yeast or human Sec61 $\beta$ (Feng et al., 2007; Leroux and Rokeach, 2008). Whether the translocation role associated with the TM of Sec61 $\beta$ is more important in other eukaryotic organisms is yet to be determined.

The cytosolic domain of Sec61 $\beta$ has been proposed to interact with ribosomes or exocyst complexes (Levy et al., 2001; Lipschutz et al., 2003; Toikkanen et al., 2003). Because Sec61 $\beta$ integrates into the ER membrane as a tailanchored protein, it also frequently associates with cytosolic chaperones before membrane insertion (Abell et al., 2007). Our results add microtubules to the list of cytSec61 $\beta$ binding partners. Overexpression of Sec61 $\beta$ causes bundling between the ER and microtubules, endogenous Sec61 precipitates with reassembled microtubules, and purified cytSec61 $\beta$ co-sediments with microtubules formed in vitro using purified tubulin. The interaction requires the middle region of cytSec61 $\beta$, which has a poorly conserved sequence but bears several basic residues and may directly engage tubulin, which contains an acidic tail. Interestingly, the interaction is inhibited when a RFP tag is added to the $\mathrm{N}$-terminus of Sec61 $\beta$, explaining why this activity was not seen previously (Sec61 $\beta$ is most commonly used in the form of a GFP/RFP fusion protein as an ER marker for live cell imaging).

The ER-microtubule association is thought to play a key role in ER morphogenesis and positioning (Goyal and Blackstone, 2013; Terasaki et al., 1986). However, due to the redundancy of microtubule-binding proteins on the $E R$, individual depletion rarely causes the morphological ER defects that occur when microtubules are mostly depolymerized. Consistently, knocking down Sec61 $\beta$ does not alter ER morphology, but causes ER stress. Restoration of the ER homeostasis is only achieved when wild type Sec61 $\beta$ or the chimera MTB ${ }^{\text {Climp63 }}-\mathrm{TM}^{\text {Sec61 }} \beta$ is reintroduced, implicating an involvement of ER-microtubule interaction in ER homeostasis, instead of ER shaping. Poor expression of the microtubule-binding mutants of Sec61 $\beta$ limits our analysis and leaves the possibility that cytSec61 is critical for other functions.
We also found that Sec61 $\beta$ stabilizes the ribosometranslocon association. These findings are consistent with previous reports showing that ER stress is triggered when ribosomal membrane-targeting is reduced (Gamerdinger et al., 2015). The stress is possibly caused by a shortage of necessary factors for maintaining ER homeostasis and/or mistakes resulting from premature separation of the ribosome-translocon complex. It is also likely that loss of Sec61 $\beta$ interferes with recently reported functional linkage between translocon and IRE1 (Plumb et al., 2015; Sundaram et al., 2017), which in turn triggers UPR. However, IRE1 engages translocon mainly through its TM segment, whether cytSec61 $\beta$ is involved remains to be investigated.

Another ER sheet-enriched protein that interacts with microtubules is Climp63. The microtubule association by Climp63 has been proposed to regulate the mobility of the translocon and, thus, may indirectly regulate the stability of the translocating complex. We found that depletion of either protein increases translocon mobility. However, depletion of Climp63 does not cause ER stress as seen with Sec61 $\beta$, suggesting that the microtubule-binding ability of Sec61 $\beta$ has a direct impact on translocon, and that of Climp63 may have other functions, such as positioning ER sheets in the perinuclear region.

Our findings partly explain why Sec61 $\beta$ is essential in higher eukaryotes. Sec61 $\beta$ has also been reported to have specific roles, such as regulating the transport of Gurken, an EGF homolog in Drosophila, to the plasma membrane (Kelkar and Dobberstein, 2009), and its involvement in the inner nuclear membrane transport of EGFR (Liao and Carpenter, 2007; Liao and Carpenter, 2009; Wang et al., 2010). Whether these activities are associated with the microtubulebinding ability identified here remains to be tested. Notably, C. elegans lines expressing Sec61 $\beta$ can only be obtained when vectors are injected at a very low level, implying that overexpression of Sec61 $\beta$ is hazardous and its level needs to be fine-tuned in higher organisms.

\section{MATERIALS AND METHODS}

\section{Constructs}

Fragments of human SEC61B were amplified from its cDNAs and connected using overlap PCR to generate truncations and chimeras. MTB domain of Climp63 (residues 1-80) was amplified from a plasmid coding mouse Climp63. For mammalian cell expression, the indicated fragments were PCR-amplified with an $\mathrm{N}$ - or C-terminal HA tag and ligated into pcDNA4/TO or pcDNA5/TO vector. The plasmid $\mathrm{mEmerald-Ensconsin} \mathrm{is} \mathrm{a} \mathrm{gift} \mathrm{from} \mathrm{Dong} \mathrm{Li's} \mathrm{lab.} \mathrm{For} \mathrm{Caenorhabditis}$ elegans expression, y38f2ar. 9 containing its 3 '-untranslated region ( $3^{\prime}-\mathrm{UTR}$ ) was amplified and subcloned into pPD49.26 vector with the promoter of hyp7 and cherry on the $\mathrm{N}$ terminus. The rescue fragments, which were the same with those in mammalian cells, were subcloned into pPD49.26 vector with the promoter of nfya-1. For protein purification, the indicated fragments were subcloned into pSUMO vector. 
siRNAs, shRNAs and gRNA for indicated proteins

SiRNA oligonucleotides targeting Sec61 $\beta$ (Wang et al., 2010), REEP1 and nonspecific siRNA control were purchased from RiboBio. The siRNA sequences are as following: Sec61 $\beta$ siRNA \#1, 5'GCAAGUACACUCGUUCGUA-3'; Sec61 $\beta$ siRNA \#2, 5'-CUGUAA GCUUGCUGUUUUA-3'; Sec61 $\beta$ siRNA for M3/18 cells, 5'-GCAAGUACACACGCUCAUA-3'; REEP1 siRNA \#1, 5'-GGCUGGUGGUGCUUAUAUU-3'; REEP1 SiRNA \#2, 5'-CCUCCUUUACAGGA AGUUU-3'; Climp63 siRNA for M3/18 cells, 5'-CCAAGUCCAUCAAUGACAA-3' (Nikonov et al., 2007). The shRNA coding plasmids were purchased from Sigma. The shRNA coding sequences are as following: Sec61 $\beta$ shRNA \#1, 5'-CCGGCAGTATTGGTTATGAGTCTTCCTCGAGGAAGACTCATAACCAATACTGTTTTTTG-3'; Sec61 $\beta$ shRNA \#2, 5'-CCGGCCCAACATTTCTTGGACCAAACTC GAGTTTGGTCCAAGAAATGTTGGGTTTTTTG-3'. The sequence of gRNA used in U2OS Climp63 deletion cell line is $5^{\prime}$ CGCCGCGCCCGCCATGCCCT-3'.

Cell culture, transfection, and co-immunoprecipitation

COS-7 cells (ATCC), U2OS cells (ATCC), MEF cells and M3/18 cells (a gift from Gert Kreibich's group) were maintained in Dulbecco's Modified Eagle's medium (DMEM; Invitrogen) supplemented with $10 \%$ fetal bovine serum (Gibico) at $37{ }^{\circ} \mathrm{C}$ (but M3/18 cells at $39.5{ }^{\circ} \mathrm{C}$ ) in $5 \% \mathrm{CO}_{2}$. Flp-In ${ }^{\mathrm{TM}} \mathrm{T}-\mathrm{REx}^{\mathrm{TM}}-293$ (Invitrogen) expression cell lines were generated following Invitrogen's protocol and maintained in DMEM (Invitrogen) with 10\% fetal bovine serum (HyClone), $2 \mathrm{mmol} / \mathrm{L}$ L-glutamine (Invitrogen), $15 \mu \mathrm{g} / \mathrm{mL}$ Blasticidin, $100 \mu \mathrm{g} / \mathrm{mL}$ Hygromycin and Penicillin-Streptomycin (Invitrogen) at $37{ }^{\circ} \mathrm{C}$ in $5 \% \mathrm{CO}_{2}$. The Sec61 $\beta$ shRNA stable cell lines were generated following the pLKO.1 protocol (Addgene). Transfections were performed using TurboFect (Thermo) for plasmids and Lipofectamine RNAiMAX (Invitrogen) for siRNAs according to the manufacturer's instructions. For co-immunoprecipitation experiments, $45 \%$ confluent $M 3 / 18$ cells were transfected with indicated siRNAs and harvested $48 \mathrm{~h}$ later in IP buffer $(25 \mathrm{mmol} / \mathrm{L}$ HEPES pH 7.4, 150 $\mathrm{mmol} / \mathrm{L} \mathrm{KAC}, 2 \mathrm{mmol} / \mathrm{L} \mathrm{Mg}(\mathrm{AC})_{2}$ and protease inhibitors) containing $1 \%$ digitonin. Cell lysates were incubated with anti-GFP agarose $(\mathrm{MBL})$ for $2 \mathrm{~h}$ at $4{ }^{\circ} \mathrm{C}$. Washed precipitates were separated by SDSPAGE and immunoblotted with anti-GFP and anti-Sec61 $\beta$ antibodies (Sigma).

\section{Strains}

Caenorhabditis elegans were cultured according to standard techniques (Brenner, 1974). The following strains were used in this work: zcls4 (Phsp-4::GFP) and qx/s439 (Phpy7::gfp::tram-1). All experiments were performed at $20{ }^{\circ} \mathrm{C}$ unless otherwise noted.

\section{Immunofluorescence and confocal microscopy}

COS-7 cells or U2OS cells were fixed with $4 \%$ paraformaldehyde (PFA) in PBS for 25 min, permeabilized with $0.1 \%$ Triton X-100/PBS for $10 \mathrm{~min}$, and blocked with $3 \% \mathrm{BSA}$ for $1 \mathrm{~h}$ at room temperature. Fixed cells were then incubated with primary antibodies for $1 \mathrm{~h}$ at room temperature or overnight at $4{ }^{\circ} \mathrm{C}$, including rabbit anti-calreticulin (Abcam; 1:800), mouse anti-Tubulin (Thermo; 1:200), rabbit anti-Tubulin (Abcam; 1:1000), mouse anti-HA (Sigma; 1:500), rabbit
anti-HA (Abcam; 1:1000), mouse anti-GM130 (BD; 1:500) and mouse anti-TOM20 (BD; 1:500), followed by incubation with various fluorophore-conjugated secondary antibodies (Alexa Fluor 488-conjugated anti-rabbit or mouse, Alexa Fluor 568-conjugated anti-mouse or rabbit, Invitrogen) for $1 \mathrm{~h}$ at room temperature. All images were captured on Leica TCS SP5 or Zeiss LSM700 confocal microscope with a $63 \times$ objective. Brightness and contrast were adjusted across the entire image using Adobe Photoshop.

\section{Microtubule co-sedimentation assay}

For in vivo assay, following 10 min's incubation on ice in $500 \mu \mathrm{L} \mathrm{MME}$ buffer (100 mmol/L MES pH 6.8, $1 \mathrm{mmol} / \mathrm{L} \mathrm{MgCl}_{2}, 1 \mathrm{mmol} / \mathrm{L}$ EGTA, 1 $\mathrm{mmol} / \mathrm{L}$ DTT and protease inhibitor) containing $1 \%$ Trition $\mathrm{X}-100$, COS-7 cells from a 6-cm dish were homogenized by the tight-fitted Dounce homogenizer for 150 strokes, and then placed on ice for 30 $\min$ before centrifugation for $10 \mathrm{~min}$ at $20,000 \times \mathrm{g}$. The supernatant was added to $30 \mu \mathrm{mol} / \mathrm{L}$ paclitaxel (Sigma) and $1 \mathrm{mmol} / \mathrm{L}$ GTP (Sigma) in a $100 \mu \mathrm{L}$ reaction volume followed by incubation at $37^{\circ} \mathrm{C}$ for $30 \mathrm{~min}$, and the mixture was loaded over the MME Cushion buffer (100 mmol/L MES pH 6.8, $1 \mathrm{mmol} / \mathrm{L} \mathrm{MgCl} 2,1 \mathrm{mmol} / \mathrm{L}$ EGTA, $1 \mathrm{mmol} /$ L DTT, $20 \%$ glycerol and protease inhibitors) containing $30 \mu \mathrm{mol} / \mathrm{L}$ paclitaxel and centrifuged at $32{ }^{\circ} \mathrm{C}$ for $50 \mathrm{~min}$ at $100,000 \times \mathrm{g}$. The negative control was incubated on ice without GTP and paclitaxel, and centrifuged at $4{ }^{\circ} \mathrm{C}$ for $50 \mathrm{~min}$ at $100,000 \times \mathrm{g}$. The pellet (containing microtubules and associated proteins) and supernatant fractions were then collected and examined by Western blotting. For in vitro assay, microtubules were assembled with $5 \mu \mathrm{mol} / \mathrm{L}$ bovine brain tubulin (Cat. \#TL238, Cytoskeleton; a gift from Jun Zhou's lab) in $100 \mu \mathrm{L}$ BRB80 buffer ( $80 \mathrm{mmol} / \mathrm{L}$ PIPES pH 6.8, 1 mmol/L EGTA, 1 $\mathrm{mmol} / \mathrm{L} \mathrm{MgCl} 2,5 \%$ glycerol and protease inhibitor) in the presence of $1 \mathrm{mmol} / \mathrm{L}$ GTP at $37{ }^{\circ} \mathrm{C}$ for $30 \mathrm{~min}$, and then added to $30 \mu \mathrm{mol} / \mathrm{L}$ paclitaxel and $1.5 \mu \mathrm{mol} / \mathrm{L}$ purified protein (centrifuged at $4{ }^{\circ} \mathrm{C}$ for 10 $\min$ at $100,000 \times \mathrm{g}$ ) followed by incubation for another $20 \mathrm{~min}$ at $37^{\circ}$ C. The reaction mixture was then analyzed as above.

Protein expression, purification, and pull-down assay

The cytosolic domain of human Sec61 $\beta$ and its $\Delta 20-44$ truncation fused with an N-terminal cleavable His-SUMO tag followed by an HA tag were expressed in Escherichia coli. The cells were lysed in lysis buffer $(50 \mathrm{mmol} / \mathrm{L}$ Tris $\mathrm{pH} 8.0,300 \mathrm{mmol} / \mathrm{L} \mathrm{NaCl}, 2 \mathrm{mmol} / \mathrm{L} \beta$-mercaptoethanol and $20 \mathrm{mmol} / \mathrm{L}$ imidazole) containing $1 \mathrm{mmol} / \mathrm{L} \mathrm{PMSF}$. The proteins were isolated with Ni-NTA, washed, and eluted with $300 \mathrm{mmol} / \mathrm{L}$ imidazole in lysis buffer. The His-SUMO tag was cleaved with His-tagged SUMO protease Ulp1p and removed by NiNTA chromatography followed by gel filtration. For pull-down assay, $5 \mu \mathrm{mol} / \mathrm{L}$ tubulin and $1.5 \mu \mathrm{mol} / \mathrm{L}$ purified protein were precipitated with anti-HA agarose (Sigma) in IP buffer $(50 \mathrm{mmol} / \mathrm{L}$ Tris $\mathrm{pH} 7.5$, $150 \mathrm{mmol} / \mathrm{L} \mathrm{NaCl}, 1 \mathrm{mmol} / \mathrm{L}$ EDTA, 30\% glycerol and protease inhibitors) containing $1 \% \mathrm{NP}-40$ for $2 \mathrm{~h}$ at $4{ }^{\circ} \mathrm{C}$. Washed precipitates were separated by SDS-PAGE and immunoblotted with anti-HA and anti-Tubulin antibodies (Abcam).

\section{RNA isolation and RT-PCR}

Cells were lysed using Trizol (Invitrogen) and total RNA was collected. cDNA reverse-transcribed from poly-A mRNA was used as 
template for PCR with the following primers: specific for human and monkey XBP1, 5'-CCTTGTAGTTGAGAACCAGG-3' and 5'GGGGCTTGGTATATATGTGG-3' (Szczesna-Skorupa et al., 2004); specific for mouse XBP1, 5'-CCTTGTGGTTGAGAACCAGG-3' and 5'-GAGGCTTGGTGTATACATGG-3'; specific for monkey REEP1 \#1, 5'-TTGTAGCCTGGCTGCTGTCTCC-3' and 5'-AAGCAGCCATCACAGCCGCTG-3'; monkey REEP1 \#2, 5'-GGACAGGGTGCCTT ATCAG-3' and 5'-ACTCCTGGACATCTTAGGCTG-3'; for monkey GAPDH, 5'-GAAGGTGAAGGTCGGAGTCA-3' and 5'-GAAGATGGTGATGGGATTTC-3'. PCR products were resolved on a $2.5 \%$ agarose/1× TAE gel. A hybrid amplicon species consisting of unspliced $X B P 1$ annealed to spliced $X B P 1$ was also produced through the PCR and was visible as a slower migrating band above the unspliced amplicon (Li et al., 2010).

\section{RNAi and rescue assay in $C$. elegans}

To determine the localization of Y38F2AR.9, the cherry::y38f2ar.9 construct was injected into gfp::tram-1 animals at the concentration of $1 \mathrm{ng} / \mathrm{\mu L}$ and pRF4(rol-6[su1006]) was co-injected. The F1 animals were checked with Zeiss LSM710 META confocal microscope. For RNAi injection experiments, single-stranded RNA was transcribed from T7- and SP6-flanked PCR templates. ssRNAs were then annealed and injected into animals carrying Phsp-4::GFP. The F1 animals were checked. The DNA template used for RNA synthesis was y38f2ar.9 (YAC Y38F2AR: nt 56335-56636). For rescue assay, the indicated construct was injected into the Phsp-4::GFP worms together with pRF4(rol-6[su1006]) and y38f2ar.9RNAi was then injected into the F2 animals. The F3 animals were checked with Zeiss LSM710 META confocal microscope.

\section{Fluorescence recovery after photobleaching}

$\mathrm{M} 3 / 18$ cells were seeded and grown overnight at $39.5^{\circ} \mathrm{C}$ on glassbottom 35-mm tissue culture dishes (MatTek) in complete growth medium. After siRNA transfection for $48 \mathrm{~h}$, the cells were ready for FRAP at $39.5{ }^{\circ} \mathrm{C}$ in $5 \% \mathrm{CO}_{2}$. FRAP experiments were performed on a Leica TCS SP5 confocal microscope as previously described (Nikonov et al., 2002).

Isolation of cytosolic and membrane-bound ribosomes

U2OS cells were seeded on two 15-cm plates for each group and allowed to grow to $100 \%$ confluence. $100 \mu \mathrm{g} / \mathrm{mL}$ of cycloheximide was added to the cells for $15 \mathrm{~min}$ before harvest as described (Zhang and Zhou, 2012). Cells were resuspended in Polysome

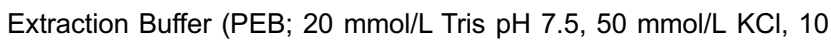
$\mathrm{mmol} / \mathrm{L} \mathrm{MgCl}_{2}, 1 \mathrm{mmol} / \mathrm{L} \mathrm{DTT}, 100 \mu \mathrm{g} / \mathrm{mL} \mathrm{CHX}, 500 \mathrm{U} / \mathrm{mL}$ RNasin and protease inhibitors) containing $0.008 \%(w / v)$ digitonin, incubated for $5 \mathrm{~min}$ on ice (Gamerdinger et al., 2015) and centrifuged at 800 rpm for $4 \mathrm{~min}$. The supernatant containing cytosolic ribosomes was collected. After two washing steps in PEB buffer, membrane-bound ribosomes were released by incubating pellets in PEB buffer supplemented with $1 \%(v / v)$ Triton X-100 for 30 min on ice. After centrifugation at $14,000 \mathrm{rpm}$ for $30 \mathrm{~min}$, the supernatant containing membrane-bound ribosomes was collected. The cytosolic and membrane fractions were then loaded on a $10 \%-50 \%$ linear sucrose gradient and sedimented in a SW41 rotor at $247,600 \times \mathrm{g}$ for $2 \mathrm{~h}$ at $4{ }^{\circ}$
C. The gradients were fractionated using a piston gradient fractionator (BioComp Instruments, Fredericton, NB, Canada) and UV absorbance at $254 \mathrm{~nm}$ was monitored by a UV-Monitor (BioRad, Hercules, CA).

\section{ACKNOWLEDGEMENTS}

We thank Dr. Jun Zhou for reagents and help with microtubule sedimentation assay, Dr. Gert Kreibich for M3/18 cells, Dr. Dong Li for mEmerald-Ensconsin plasmid and Xin Zhou and Fang Chen for technical assistance. J.H. is supported by the National Key Research and Development Program (Grant No. 2016YFA0500201), the National Natural Science Foundation of China (Grant Nos. 31225006 and 31421002), and an International Early Career Scientist grant from Howard Hughes Medical Institute.

\section{ABBREVIATIONS}

ER, endoplasmic reticulum; MTB, microtubule-binding; TG, thapsigargin; TM, transmembrane; UPR, unfolded protein response

\section{COMPLIANCE WITH ETHICS GUIDELINES}

Yimeng Zhu, Gangming Zhang, Shaoyu Lin, Juanming Shi, Hong Zhang and Junjie Hu declare that they have no conflict of interest. All institutional and national guidelines for the care and use of laboratory animals were followed.

\section{OPEN ACCESS}

This article is distributed under the terms of the Creative Commons Attribution 4.0 International License (http://creativecommons.org/ licenses/by/4.0/), which permits unrestricted use, distribution, and reproduction in any medium, provided you give appropriate credit to the original author(s) and the source, provide a link to the Creative Commons license, and indicate if changes were made.

\section{REFERENCES}

Abell BM, Pool MR, Schlenker O, Sinning I, High S (2004) Signal recognition particle mediates post-translational targeting in eukaryotes. EMBO J 23:2755-2764

Abell BM, Rabu C, Leznicki P, Young JC, High S (2007) Posttranslational integration of tail-anchored proteins is facilitated by defined molecular chaperones. J Cell Sci 120:1743-1751

Barlowe C (2010) ER sheets get roughed up. Cell 143:665-666

Bernales S, Papa FR, Walter P (2006) Intracellular signaling by the unfolded protein response. Annu Rev Cell Dev Biol 22:487-508

Brenner S (1974) The genetics of Caenorhabditis elegans. Genetics 77:71-94

Calfon M, Zeng H, Urano F, Till JH, Hubbard SR, Harding HP, Clark SG, Ron D (2002) IRE1 couples endoplasmic reticulum load to secretory capacity by processing the XBP-1 mRNA. Nature 415:92-96

Carrasco S, Meyer T (2011) STIM proteins and the endoplasmic reticulum-plasma membrane junctions. Annu Rev Biochem 80:973-1000 
Favaloro V, Spasic M, Schwappach B, Dobberstein B (2008) Distinct targeting pathways for the membrane insertion of tail-anchored (TA) proteins. J Cell Sci 121:1832-1840

Feng D, Zhao X, Soromani C, Toikkanen J, Romisch K, Vembar SS, Brodsky JL, Keranen S, Jantti J (2007) The transmembrane domain is sufficient for Sbh1p function, its association with the Sec61 complex, and interaction with Rtn1p. J Biol Chem 282:30618-30628

Finke K, Plath K, Panzner S, Prehn S, Rapoport TA, Hartmann E, Sommer T (1996) A second trimeric complex containing homologs of the Sec61p complex functions in protein transport across the ER membrane of S. cerevisiae. EMBO J 15:14821494

Friedman JR, Voeltz GK (2011) The ER in 3D: a multifunctional dynamic membrane network. Trends Cell Biol 21:709-717

Gamerdinger M, Hanebuth MA, Frickey T, Deuerling E (2015) The principle of antagonism ensures protein targeting specificity at the endoplasmic reticulum. Science 348:201-207

Goyal U, Blackstone C (2013) Untangling the web: mechanisms underlying ER network formation. Biochim Biophys Acta 1833:2492-2498

Grigoriev I, Gouveia SM, van der Vaart B, Demmers J, Smyth JT, Honnappa S, Splinter D, Steinmetz MO, Putney JW Jr, Hoogenraad CC, Akhmanova A (2008) STIM1 is a MT-plus-end-tracking protein involved in remodeling of the ER. Curr Biol 18:177-182

Harding HP, Zhang Y, Ron D (1999) Protein translation and folding are coupled by an endoplasmic-reticulum-resident kinase. Nature 397:271-274

Harding HP, Zhang Y, Bertolotti A, Zeng H, Ron D (2000) Perk is essential for translational regulation and cell survival during the unfolded protein response. Mol Cell 5:897-904

Haze K, Yoshida H, Yanagi H, Yura T, Mori K (1999) Mammalian transcription factor ATF6 is synthesized as a transmembrane protein and activated by proteolysis in response to endoplasmic reticulum stress. Mol Biol Cell 10:3787-3799

Hu J, Shibata Y, Voss C, Shemesh T, Li Z, Coughlin M, Kozlov MM, Rapoport TA, Prinz WA (2008) Membrane proteins of the endoplasmic reticulum induce high-curvature tubules. Science 319:1247-1250

Hu J, Prinz WA, Rapoport TA (2011) Weaving the web of ER tubules. Cell 147:1226-1231

Kalies KU, Rapoport TA, Hartmann E (1998) The beta subunit of the Sec61 complex facilitates cotranslational protein transport and interacts with the signal peptidase during translocation. J Cell Biol 141:887-894

Kelkar A, Dobberstein B (2009) Sec61beta, a subunit of the Sec61 protein translocation channel at the endoplasmic reticulum, is involved in the transport of Gurken to the plasma membrane. BMC Cell Biol 10:11

Klopfenstein DR, Kappeler F, Hauri HP (1998) A novel direct interaction of endoplasmic reticulum with microtubules. EMBO J 17:6168-6177

Lee K, Tirasophon W, Shen X, Michalak M, Prywes R, Okada T, Yoshida H, Mori K, Kaufman RJ (2002) IRE1-mediated unconventional mRNA splicing and S2P-mediated ATF6 cleavage merge to regulate $\mathrm{XBP} 1$ in signaling the unfolded protein response. Genes Dev 16:452-466
Leroux A, Rokeach LA (2008) Inter-species complementation of the translocon beta subunit requires only its transmembrane domain. PLoS ONE 3:e3880

Levy R, Wiedmann M, Kreibich G (2001) In vitro binding of ribosomes to the beta subunit of the Sec61p protein translocation complex. J Biol Chem 276:2340-2346

Li H, Korennykh AV, Behrman SL, Walter P (2010) Mammalian endoplasmic reticulum stress sensor IRE1 signals by dynamic clustering. Proc Natl Acad Sci USA 107:16113-16118

Liao HJ, Carpenter G (2007) Role of the Sec61 translocon in EGF receptor trafficking to the nucleus and gene expression. Mol Biol Cell 18:1064-1072

Liao HJ, Carpenter G (2009) Cetuximab/C225-induced intracellular trafficking of epidermal growth factor receptor. Cancer Res 69:6179-6183

Lipschutz JH, Lingappa VR, Mostov KE (2003) The exocyst affects protein synthesis by acting on the translocation machinery of the endoplasmic reticulum. J Biol Chem 278:20954-20960

Meyer HA, Grau H, Kraft R, Kostka S, Prehn S, Kalies KU, Hartmann E (2000) Mammalian Sec61 is associated with Sec62 and Sec63. J Biol Chem 275:14550-14557

Miyazaki K, Wakana Y, Noda C, Arasaki K, Furuno A, Tagaya M (2012) Contribution of the long form of syntaxin 5 to the organization of the endoplasmic reticulum. J Cell Sci 125:56585666

Nikonov AV, Snapp E, Lippincott-Schwartz J, Kreibich G (2002) Active translocon complexes labeled with GFP-Dad1 diffuse slowly as large polysome arrays in the endoplasmic reticulum. J Cell Biol 158:497-506

Nikonov AV, Hauri HP, Lauring B, Kreibich G (2007) Climp-63mediated binding of microtubules to the ER affects the lateral mobility of translocon complexes. J Cell Sci 120:2248-2258

Park CY, Hoover PJ, Mullins FM, Bachhawat P, Covington ED, Raunser S, Walz T, Garcia KC, Dolmetsch RE, Lewis RS (2009) STIM1 clusters and activates CRAC channels via direct binding of a cytosolic domain to Orai1. Cell 136:876-890

Park SH, Zhu PP, Parker RL, Blackstone C (2010) Hereditary spastic paraplegia proteins REEP1, spastin, and atlastin-1 coordinate microtubule interactions with the tubular ER network. J Clin Invest 120:1097-1110

Plumb R, Zhang ZR, Appathurai S, Mariappan M (2015) A functional link between the co-translational protein translocation pathway and the UPR. Elife 4:e07426

Rapoport TA (2007) Protein translocation across the eukaryotic endoplasmic reticulum and bacterial plasma membranes. Nature 450:663-669

Ron D, Walter P (2007) Signal integration in the endoplasmic reticulum unfolded protein response. Nat Rev Mol Cell Biol 8:519-529

Schroder M, Kaufman RJ (2005) The mammalian unfolded protein response. Annu Rev Biochem 74:739-789

Shibata Y, Voeltz GK, Rapoport TA (2006) Rough sheets and smooth tubules. Cell. 126:435-439

Shibata Y, Shemesh T, Prinz WA, Palazzo AF, Kozlov MM, Rapoport TA (2010) Mechanisms determining the morphology of the peripheral ER. Cell 143:774-788 
Staehelin LA (1997) The plant ER: a dynamic organelle composed of a large number of discrete functional domains. Plant $\mathrm{J}$ 11:1151-1165

Stefanovic S, Hegde RS (2007) Identification of a targeting factor for posttranslational membrane protein insertion into the ER. Cell 128:1147-1159

Sundaram A, Plumb R, Appathurai S, Mariappan M (2017) The Sec61 translocon limits IRE1alpha signaling during the unfolded protein response. Elife 6:12

Szczesna-Skorupa E, Chen CD, Liu H, Kemper B (2004) Gene expression changes associated with the endoplasmic reticulum stress response induced by microsomal cytochrome p450 overproduction. J Biol Chem 279:13953-13961

Tabas I, Ron D (2011) Integrating the mechanisms of apoptosis induced by endoplasmic reticulum stress. Nat Cell Biol 13:184190

Terasaki M, Chen LB, Fujiwara K (1986) Microtubules and the endoplasmic reticulum are highly interdependent structures. J Cell Biol 103:1557-1568

Toikkanen JH, Miller KJ, Soderlund H, Jantti J, Keranen S (2003) The beta subunit of the Sec61p endoplasmic reticulum translocon interacts with the exocyst complex in Saccharomyces cerevisiae. J Biol Chem 278:20946-20953

Valcarcel R, Weber U, Jackson DB, Benes V, Ansorge W, Bohmann D, Mlodzik M (1999) Sec61beta, a subunit of the protein translocation channel, is required during Drosophila development. J Cell Sci 112(Pt 23):4389-4396

Vedrenne C, Klopfenstein DR, Hauri HP (2005) Phosphorylation controls CLIMP-63-mediated anchoring of the endoplasmic reticulum to microtubules. Mol Biol Cell 16:1928-1937
Voeltz GK, Rolls MM, Rapoport TA (2002) Structural organization of the endoplasmic reticulum. EMBO Rep 3:944-950

Voeltz GK, Prinz WA, Shibata Y, Rist JM, Rapoport TA (2006) A class of membrane proteins shaping the tubular endoplasmic reticulum. Cell 124:573-586

Walter P, Ron D (2011) The unfolded protein response: from stress pathway to homeostatic regulation. Science 334:1081-1086

Wang YN, Yamaguchi H, Huo L, Du Y, Lee HJ, Lee HH, Wang H, Hsu JM, Hung MC (2010) The translocon Sec61beta localized in the inner nuclear membrane transports membrane-embedded EGF receptor to the nucleus. J Biol Chem 285:38720-38729

Wang S, Romano FB, Field CM, Mitchison TJ, Rapoport TA (2013) Multiple mechanisms determine ER network morphology during the cell cycle in Xenopus egg extracts. J Cell Biol 203:801-814

Wang X, Li S, Wang H, Shui W, Hu J (2017) Quantitative proteomics reveal proteins enriched in tubular endoplasmic reticulum of Saccharomyces cerevisiae. Elife 6:e23816

Yoshida H, Matsui T, Yamamoto A, Okada T, Mori K (2001) XBP1 mRNA is induced by ATF6 and spliced by IRE1 in response to ER stress to produce a highly active transcription factor. Cell 107:881-891

Zhang H, Hu J (2016) Shaping the endoplasmic reticulum into a social network. Trends Cell Biol 26:934-943

Zhang H, Zhou M (2012) Polysome preparation, RNA isolation and analysis. Bio Protoc 2:e286

Zurek N, Sparks L, Voeltz G (2011) Reticulon short hairpin transmembrane domains are used to shape ER tubules. Traffic 12:28-41 